ARTICLE HISTORY: Received: December 4, 2021 Accepted: January 28, 2022 Published: February 4, 2022

УДК 581.1

РОЛЬ ПАРАМЕТРОВ МАТЕМАТИЧЕСКИХ МОДЕЛЕЙ, ОПИСЫВАЮЩИХ ФОРМУ
КАПИЛЛЯРНЫХ ВЕТВЕЙ РАСТЕНИЙ В КРИВОЛИНЕЙНЫХ КАПИЛЛЯРАХ.

И.А.Кипнис *, Ю.М.Вернигоров **, Д. В.Калашников ***, А.Б.Гордеева ****

* член-корреспондент МАНЭБ, кандидат технических наук, зам. генерального директора по научной работе ООО «Научно - производственная фирма «КАСИОР», Москва

**академик МАНЭБ, доктор технических наук, профессор, Донской государственный технический университет. Ростов-на-Дону *** кандидат сельскохозяйственных наук, дочент Российский государственный аграрный университет.

Московская сельскохозяйственная академия им. К.А. Тимирязева, Москва

**** кандидат технических наук, доиент, Донской государственный технический университет. Ростов-на-Дону

\title{
THE ROLE OF PARAMETRS OF MATHEMATICAL MODELS DESCRIBING THE SHAPE OF THE CAPILLARY BRANCHES OF PLANTS IN CURVILINEAR CAPILLARIES.
}

\author{
I.A.Kipnis, Y.M.Vernigorov, D. V.Kalashnikov, A.B.Gordeeva
}

\begin{abstract}
Аннотация. В ряде работ высказано предположение, что вода в растениях поднимается за счет сил, создаваемых в мениске капиллярных каналов. Математическая модель продвижения воды в многоуровневых криволинейных капиллярах позволяет рассчитать подъем воды, как в капиллярах каждого уровня, так и в центральном прямом капилляре. Установлено, что продвижение воды в системе капилляров зависит от количества уровней, расстояния между ними и кривизны ветвей капилляров. Установлено, что уменьшение расстояния между уровнями приводит к увеличению продвижения воды в каждой из боковых ветвей. В многоуровневых капиллярных системах продвижение воды в капиллярах высших уровней меньше, чем в капиллярах первого уровня. Линия, проходящая через мениски воды в капиллярах, образует фигуру, совпадающую с формой листа или кроны дерева.

Annotation. A number of studies suggested that water rises in plants due to forces generated in the meniscus of the capillary channels. Mathematical model of promotion of water in multilevel curvilinear capillaries allows to calculate the rise in water as in the capillaries of each level and at the central forward capillary. It is found that water in the capillaries promotion system depends on the number of levels and the spacing of curvature capillaries branches. It is found that water in the capillaries promotion system depends on the number of levels and the spacing of curvature capillaries branches. It is found that reducing the distance between the layers increases the promotion of water in each of the lateral branches. In multi-level systems of promotion of capillary water in the capillaries of the higher levels is less than in the capillaries of the first level. The line passing through the water menisci in the capillaries, forming a figure that coincides with the shape of a tree or leaf.
\end{abstract}

Ключевые слова: многоуровневый криволинейный капилляр - ветвь-ксилема - транспирация- растениемодель.

Keywords: multi-level curvilinear capillary, branch, xylem, transpiration, plant, model.

Введение. Ранее было показано [1,2] , что для криволинейных ветвей, описываемых уравнением вида $\mathrm{y}=\mathrm{k}$ $\mathrm{x}^{\mathrm{n}}$ распределение воды в криволинейных ветвях и вертикальном капилляре аналогично полученному в [3]. Отличие состоит в том, что при прочих равных условиях объем воды в криволинейных капиллярах всегда больше, чем в прямолинейных. Показано, что величина продвижения воды в ветвях является функцией угла наклона касательной к мениску воды в капилляре к горизонтали.

Цель работы. Определение роли параметров математических моделей, описывающих форму капиллярных ветвей в многоуровневых системах криволинейных капилляров.

Основная часть. Для определения координат менисков воды в криволинейных ветвях разных уровней относительно осей $y$ и $x$, связанных, соответственно, с вертикальным капилляром, необходимо найти уравнение касательной к мениску для функции, заданной уравнением $y(x)=h_{1}+k x^{\mathrm{n}}$.

Уравнение касательной к графику функции в общем виде [4] имеет вид 


$$
y=f(x)+f^{\prime}\left(x_{0}\right)\left(x-x_{0}\right)
$$

Определим абсциссу $x_{0}$ в точке касания касательной мениска, считая угол наклона касательной $\theta$ к прямой $y=0$ заданным.

Очевидно, что

$f^{\prime}\left(x_{0}\right)=\operatorname{tg} \theta=k n x_{0}^{(n-1)}(2)$

откуда

$$
x_{0}=\sqrt[(n-1)]{\frac{\operatorname{tg} \theta}{\operatorname{kn} n}}
$$

После несложных преобразований (с учетом $M$ уровней $(1 \leq m \leq M)$ капиллярной системы) уравнение касательной (1) может быть записано в виде

$$
\begin{aligned}
& y=m h_{1}+k\left(\sqrt[(n-1)]{\frac{\operatorname{tg} \theta(n n)}{\ln n}}\right)^{n}+k n\left(\sqrt[(n-1)]{\frac{\operatorname{tg} \theta(n n)}{\operatorname{kn}}}\right)^{(n-1)}\left(x-\sqrt[[n-1)]{\frac{\operatorname{tg} \theta(n n)}{\operatorname{kn}}}\right)= \\
& =m h_{1}+(1-n) k\left(\sqrt[(n-1)]{\frac{\operatorname{tg} \theta(m i)}{k n}}\right)^{n}+k n\left(\sqrt[(n-1)]{\frac{\operatorname{tg} \theta(m)}{k n}}\right)^{(n-1)} x
\end{aligned}
$$

Полагая $y=0$, получим значение х в точке пересечения касательной оси абсцисс

$$
x_{\mid y=0}=-\left(m h_{1}+(1-n) k\left(\sqrt[(n-1)]{\frac{\operatorname{tg} \theta(n n)}{k n}}\right)^{n}\right) /\left(k n\left(\sqrt[(n-1)]{\frac{\operatorname{tg} \theta(n n)}{\operatorname{kn}}}\right)^{(n-1)}\right)
$$

Далее получим значение величины ординаты уо водяного мениска в $m$-ой ветви

$$
\begin{aligned}
& y_{0}=\left(x_{0}-x_{\mid y=0}\right) \operatorname{tg} \theta^{\lfloor m\rangle}=\left[\sqrt[[n-1)]{\frac{\operatorname{tg} \theta(n n))}{\ln n}}+\left(m h_{1}+\right.\right. \\
& \left.\left.+(1-n) k\left(\sqrt[[n-1)]{\frac{\operatorname{tg} \theta^{(n n)}}{k n}}\right)^{n}\right) /\left(k n\left(\sqrt[(n-1)]{\frac{\operatorname{tg} \theta(n n)}{k n}}\right)^{(n-1)}\right)\right] \operatorname{tg} \theta^{[m]}
\end{aligned}
$$

Воспользовавшись расчетами в [1], можно получить соотношения для определения координат водного мениска в виде
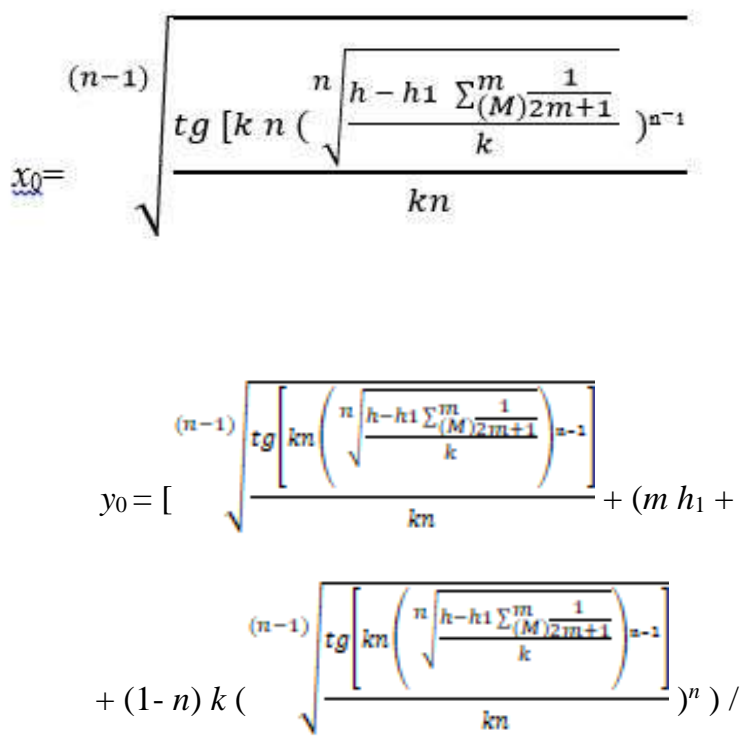


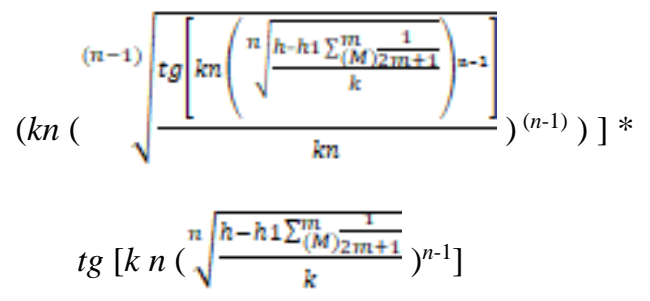

Аналогично могут быть получены координаты водных менисков в капиллярах, описываемых другими математическими функциями. Из полученных соотношений следует, что продвижение воды в криволинейных капиллярах, описываемых функцией $y(x)=h_{1}+k x^{n}$, зависит от пяти независимых величин: $k, n, M, h$ и $h_{1}$, каждая из которых может изменяться в широких пределах.

Рассмотрим конкретный пример. На фотографии рис.1 можно видеть, что попарно симметрично отходящие от ствола боковые ветви, лежат в одной плоскости и в основном имеют вид квадратичной параболы.

Принимая в полученных соотношениях $n=2, k=1$, количество уровней $M$ будем изменять от 2 до 5 , определим величины продвижения воды в криволинейных капиллярах для систем с разным количеством уровней и их отношение к первой нижней ветви для разных значений $k_{1}$. Поскольку входящие под знак радикала в тригонометрических функциях величины $h$ и $h_{1}$ численно не определены, поступим следующим образом. Введем величину $k_{l}$, которую определим как

$$
h_{1}=k_{1} h, 0 \leq k_{1} \leq 1
$$

Тогда неопределенной останется одна величина $h$. Для устранения этой неопределенности примем масштабную единицу вдоль координатных осей $x$ и у равной $h$.

С учетом принятых условий получим следующие соотношения продвижения воды, например, для пятиуровневой системы

4

$$
\begin{aligned}
& L_{1(\mathrm{mp})}^{(5, j)}=L_{1 / \pi \mathrm{B})}^{(5)}=\left(1-0,091 k_{1}\right) /\left(1-\cos \operatorname{arctg}\left(2 \sqrt[2]{1-0,091 k_{1}}\right)\right) \\
& L_{2(\operatorname{mp})}^{[(5))}=L_{2(\pi \mathrm{B})}^{(5)}=\left(1-0,203 k_{1}\right) /\left(1-\cos \operatorname{arctg}\left(2 \sqrt[2]{1-0,203 k_{1}}\right)\right)
\end{aligned}
$$

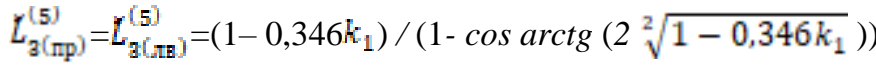

$$
\begin{aligned}
& L_{4(\mathrm{mp})}^{[5])}=L_{4(\pi \mathrm{g})}^{(5)}=\left(1-0,546 k_{1}\right) /\left(1-\cos \operatorname{arctg}\left(2 \sqrt[2]{1-0,546 k_{1}}\right)\right) \\
& L_{5(\operatorname{mp})}^{(5 j)}=L_{5(\mathrm{IBg})}^{(5)}=\left(1-0,88 k_{1}\right) /\left(1-\cos \operatorname{arctg}\left(2 \sqrt[2]{1-0,88 k_{1}}\right)\right) \\
& h_{506}^{[5]}=1+4,12 k_{1}
\end{aligned}
$$

Как следует из (10) - (14) продвижение воды в криволинейных частях капилляра существенно зависит от угла наклона касательной к мениску. При увеличении количества уровней силы поверхностного натяжения в водном мениске каждого вышележащего уровня поднимают больший объем воды, чем силы поверхностного натяжения в менисках нижележащих уровней. Увеличение $k_{1}$, соответствующее увеличению вертикальных промежутков между ветвями, также приводит к увеличению объема поднимаемой воды в вертикальной части системы, что в свою очередь приводит к уменьшению продвижения воды в криволинейных ветвях.

Как и в случае с прямолинейными капиллярами, наибольшее продвижение воды происходит в криволинейных капиллярах нижнего уровня. Увеличение вертикальных промежутков между уровнями также приводит к уменьшению продвижения воды в криволинейных ветвях. Общим для прямолинейных и криволинейных капилляров является то, что линия, соединяющая водяные мениски в боковых ветвях и вертикальном капилляре, образует фигуру, напоминающую форму дерева или листа. Отличие в полученных фигурах состоит в том, что в криволинейных капиллярных системах продвижение воды в капиллярах высших уровней относительно капилляра первого уровняв больше по сравнению с прямолинейными капиллярами тех

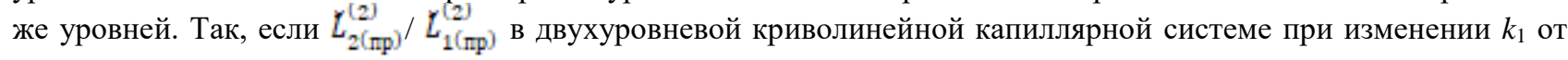
0,2 до 0,8 уменьшается от 0,94 до 0,72, то для прямолинейного капилляра уменьшение будет от 0,92 до 0,62. Для пятого уровня изменения $L_{m(m p)}^{\left[5 l^{\prime}\right.} / L_{1(m p)}^{[5]}$ составят от 0,89 до 0,53 в криволинейной и от 0,84 до 0,32 в 
прямолинейной боковых ветвях. Следует также отметить, что по мере увеличения количества уровней в системе разница в величине продвижения воды в нижних уровнях криволинейного и прямолинейного капилляров уменьшается. Так, например, если в двухуровневой системе продвижение воды при $k_{1}=0,2$ эта разница равна 0,02 , то в пятиуровневой эта разница равна 0,01 . При $k_{1}=0,8$ эта разность составляет 0,1 и 0,04 соответственно для двухуровневой и пятиуровневой систем. Высоты подъема воды в вертикальном капилляре во всех случаях одинаковы для криволинейных и прямолинейных капиллярных систем одинаковых уровней.

Принятая нами для расчетов степенная функция $y(x)=h_{1}+k x^{\mathrm{n}}$ содержит два параметра $k$ и $n$, физический смысл которых применительно к древесным растениям не определен. В разрешении этого вопроса можно предположить следующее. В литературных источниках, например, [5], [6], [7] рассмотрены явления фото-, термо, и грави - тропизмов, совместное действие которых приводит к искривлению формы ветви и ее роста против силы тяжести. Это обусловлено действием ауксина (индолилуксусной кислоты) на клетки растений в период их роста. В частности, в [6] отмечается, что при неравномерном освещении побега светом происходит перемещение ауксина в сторону неосвещенного участка. Одновременно с этим увеличение концентрации ауксина в теневой стороне бокового побега приводит к ускорению роста клеток с его нижней стороны. Аналогичное действие оказывает и температура: активность ауксина уменьшается со стороны более нагретой части побега. Отмечается также, что повышенная концентрация ауксина изменяет структуру тканей побега в зоне действия ауксина, делая их более эластичными и способными к растяжению. Клеточные структуры побега, со стороны, обращенной к источнику света и (или) тепла, растут медленнее, и происходит изгибание побега в сторону источника. В [7] отмечается (стр.244), что воздействие ультрафиолета с длиной волны 280 нм разрушает ауксин, что также приводит к его неравномерному распределению на освещенном и теневом участке бокового побега. Описывая эти явления, авторы не отвечают на вопрос о том, до каких пор будет изгибаться боковой побег под неравномерным действием ауксина. Можно предположить, что побег будет изгибаться до тех пор, пока не примет положение параллельное падающим на него лучам света, что исключит неравномерное распределения ауксина. Отсюда следует, что угол наклона ветвей будет зависеть от места географического положения растущего дерева. В южных климатических зонах, где солнце поднимается высоко в зените, ветви должны расти более круто, чем в северных широтах. То есть имеет место «географический тропизм», а показатель $n$ в полученном выше уравнении характеризует степень этого тропизма. Коэффициент $k$ в уравнении степенной функции является фокусом кривой. Возможно, его смысл состоит в том, что по мере роста растения диаметр ствола вдоль вертикальной оси дерева не остается одинаковым и уменьшается к верхней части ствола по мере его роста. Одновременно с увеличением диаметра в нижней части ствола и увеличением длины нижних ветвей апикальные точки роста этих ветвей удаляются от ствола и ауксин уже не достигает и не оказывает действия на нижние боковые ветви вблизи их соединения со стволом. Рост и растяжение клеток происходит в этой зоне равномерно и угол наклона этих ветвей постепенно уменьшается. Одновременно для таких ветвей увеличивается фокус параболы $k<1$. В то же самое время в молодых побегах в верхней части ствола распределение ауксина в растущих побегах неравномерно и они изгибаются до тех пор, пока не станут параллельными падающим лучам света. В зависимости от угла падения световых лучей растущая ветвь может изгибаться очень круто, что соответствует уменьшению фокусного расстояния.

В природе описанное явление можно наблюдать на примере пихты Нормана (Abies nordmanniana), у которой нижние ветви отходят от ствола под небольшим углом к горизонтали, а самые верхние молодые ветви растут криволинейно. Также при омоложении растений (удалении верхней части ствола и ветвей) вновь нарастающие ветви растут криволинейно, а иногда почти параллельно стволу, что также подтверждает высказанные нами предположения.

Выводы.

1. Показано, что в криволинейных капиллярах высших растений продвижение воды кроме: фото- , термо-, грави- тропизммов, количества уровней ветвей в системе и величины промежутка между уровнями, определяется также географическим тропизмом и распределением ауксина в ветвях по мере роста растения.

2.Продвижение воды в криволинейных ветвях всегда больше продвижения воды в прямолинейных ветвях тех же уровней, исходящих из той же точки вертикального капилляра, что и криволинейная ветвь, под углом наклона равным углу наклона касательной к водному мениску в рассматриваемом уровне.

3.По мере увеличения количества уровней угол наклона касательной к менискам воды в криволинейных ветвях уменьшается по сравнению с первой криволинейной ветвью. Уменьшение этого угла показывает, что вода в криволинейных ветвях продвигается тем меньше, чем больше номер уровня.

\section{Список литературы}

1. Кипнис И.А., Капиллярная модель габитуса растений. / И.А. Кипнис, Ю.М. Вернигоров / Известия Южного федерального университета. Технические науки. №9, 2013, с 250-255.

2. Кипнис И.А. Математическая модель подъема воды в простых криволинейных капиллярах. / И.А. Кипнис, Ю.М. Вернигоров //Вестник Донского гос. техн. ун-та 2013, №5/6 (74) - с.110-118. 
3.Вернигоров, Ю.М. Математическое моделирование распределения жидкости в ветвящихся капиллярных системах /Ю.М. Вернигоров, И.А.Кипнис// Вестник Донского гос. техн. ун-та. - 2010.- Т.10. - № 8(51). -С.11951206.

4. Бронштейн, И.Н. Справочник по математике для инженеров и учащихся вузов / И.Н.Бронштейн, К.А.Семендяев//Изд. 《ЛАНЬ», Санкт-Петербург, 2009. 5. Вилли, К. Биология (Биологические процессы и законы) / К. Вилли. В. Детье. // Пер. с англ./ Н.М. Баевский, Ю.И. Лашкевич., Н.В.Обручева -Москва.: Мир 1974, 824 с.

6. Грин, Н. Биология В 3-х т. Т.2,/ Н. Грин. У.Стаут, Д.Тейлор //Пер. с англ под ред. Р. Сопера, Москва.: Мир 1990. 325 с.

7. Якушкина, Н.И. Физиология растений/ Н.И. Якушкина, Е.Ю. Бахтенко // Москва.: Гуманитарный издательский центр ВЛАДОС, 2005. - 463 с.

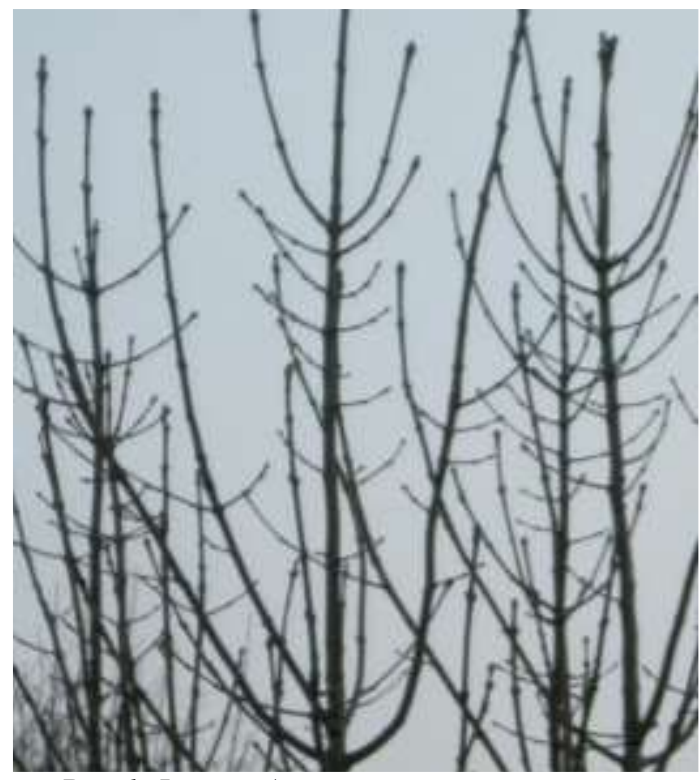

Рис.1 Форма боковых ветвей растений.

\begin{tabular}{|c|c|}
\multicolumn{2}{|c|}{ Сведения об авторе(-ах) } \\
\begin{tabular}{|c|c|}
\hline Ф. И. О. (полностью) & Кипнис Иосиф Аншелевич \\
\hline Ученая степень & Кандидат технических наук \\
\hline Ученое звание & Зам.генерального директора по научной работе \\
\hline Должность & ООО «Научно - производственная фирма «КАСИОР»» \\
\hline $\begin{array}{c}\text { Место работы, учебы } \\
\text { (полное наименование организации) }\end{array}$ & Россия, Москва, Ленинский проспект, 154 \\
\hline $\begin{array}{c}\text { Адрес места работы, учебы } \\
\text { (с указанием страны) }\end{array}$ & 89165205843 \\
\hline $\begin{array}{c}\text { Контактный телефон } \\
\text { (для иногородних с указанием } \\
\text { тел. кода города) }\end{array}$ & 119571, Москва, Ленинский проспект, 154, фирма \\
«КАСИОР»
\end{tabular} \\
\hline $\begin{array}{c}\text { Адрес, на который следует выслать авторский } \\
\text { экземпляр журнала } \\
\text { (с указанием почтового индекса) }\end{array}$ & \\
\hline
\end{tabular}

\begin{tabular}{|c|c|}
\hline Ф. И. О. (полностью) & Вернигоров Юрий Михайлович \\
\hline Ученая степень & доктор технических наук \\
\hline Ученое звание & профессор \\
\hline Должность & профессор \\
\hline Место работы, учебы & Донской государственный технический университет \\
\hline (полное наименование организации) & Россия, Ростов-на-Дону, пл.Гагарина,1 ДГТУ \\
\hline Адрес места работы, учебы & \\
\hline
\end{tabular}




\begin{tabular}{|c|c|}
\hline (с указанием страны) & 89282291508 \\
\hline $\begin{array}{c}\text { Контактный телефон } \\
\text { (для иногородних с указанием } \\
\text { тел. кода города) }\end{array}$ \\
\hline Адрес, на который следует выслать авторский \\
экземпляр журнала \\
(с указанием почтового индекса)
\end{tabular}

\begin{tabular}{|c|c|}
\hline Ф. И. О. & Калашников Дмитрий Владимирович \\
\hline Ученая степень & Кандидат сельско-хозяйственных наук \\
\hline Ученое звание & Доцент - \\
\hline Должность & $\begin{array}{c}\text { Доцент } \\
\text { Московсккий государственный аграрный университет. }\end{array}$ \\
\hline Место работы, учебы & Тимирязева \\
\hline Адрес места работы, учебы & Россия, Москва, Тимирязевская ул. 49 \\
\hline Контактный телефон & 89197751319 \\
\hline Адрес, на который следует выслать авторский \\
экземпляр журнала
\end{tabular}

\begin{tabular}{|c|c|}
\hline Ф. И. О. & Гордеева Анастасия Борисовна \\
\hline Ученая степень & Кандидат технических наук \\
\hline Ученое звание & Доцент \\
\hline Должность & Доцент \\
\hline Место работы, учебы & Донской государственный технический университет \\
\hline Адрес места работы, учебы & Россия, Ростов-на-Дону, пл.Гагарина,1 ДГТУ \\
\hline Контактный телефон & 89045097647 \\
\hline Адрес, на который следует выслать авторский & 344000 Россия, Ростов-на-Дону, \\
экземпляр журнала & пл. Гагарина, 1, ДГТУ \\
\hline
\end{tabular}

\begin{tabular}{|c|c|}
\hline \multicolumn{2}{|c|}{ Authors } \\
\hline Surname, first name, patronymic (in full) & Kipnis Iosif Anshelevich \\
\hline Academic degree & Candidate of Science in Engineering \\
\hline Candidate of Science in Engineering & Associate General Director on science \\
\hline $\begin{array}{c}\text { Place of work, studies } \\
\text { (full name of the company) }\end{array}$ & Scientific and production firm "KASIOR” ltd \\
\hline $\begin{array}{c}\text { Address of the place of work, studies } \\
\text { (including the name of the country) }\end{array}$ & Russia, Moscow, Leninskiy prospect, 154 \\
\hline $\begin{array}{c}\text { Contact telephone number } \\
\text { (for nonresidents - including area code) }\end{array}$ & 816 520 58 43 \\
\hline $\begin{array}{c}\text { Address where the author's copy should be sent } \\
\text { (including the post code) }\end{array}$ & 119571, Moscow, Leninskiy prospect, 154, firma “KASIOR” \\
\hline
\end{tabular}

\begin{tabular}{|c|c|}
\hline Surname, first name, patronymic (in full) & Vernigorov Yury Mihailovich \\
\hline Academic degree & PhD in Science \\
\hline Academic title & Professor \\
\hline Position & Professor \\
\hline $\begin{array}{c}\text { Place of work, studies } \\
\text { (full name of the company) }\end{array}$ & Don State Technical University \\
\hline $\begin{array}{c}\text { Address of the place of work, studies } \\
\text { (including the name of the country) }\end{array}$ & Russia, Rostov-on-Don, Gagarina,1 DSTU \\
\hline $\begin{array}{c}\text { Contact telephone number } \\
\text { (for nonresidents - including area code) }\end{array}$ & 8 928 229 15 08 \\
\hline Address where the author's copy should be sent & Russia,Rostov-on-Don, Gagarina,1 DSTU \\
\hline
\end{tabular}


(including the post code)

\begin{tabular}{|c|c|}
\hline Surname, first name, patronymic & Kalashnikov Dmitry Vladimirovich \\
\hline Academic degree & Candidate of Science in Agronomy \\
\hline Academic title & Docent \\
\hline Position & Docent \\
\hline Place of work, studies & Moscow Agrarian University \\
\hline Address of the place of work, studies & Russia,Moscow, Timiriazev str.49 \\
\hline Contact telephone number & +79197751319 \\
\hline Address where the author's copy should be sent & Moscow, Dmitrovskoe shosse,3-1-16 \\
\hline
\end{tabular}

\begin{tabular}{|c|c|}
\hline Surname, first name, patronymic & Gordeeva Anastasia Borisovna \\
\hline Academic degree & Candidate of Science in Engineering \\
\hline Academic title & Docent \\
\hline Position & Docent \\
\hline Place of work, studies & Don State Technical University \\
\hline Address of the place of work, studies & Russia, Rostov-on-Don, Gagarina,1 DSTU \\
\hline Contact telephone number & 89045097647 \\
\hline Address where the author's copy should be sent & Russia,Rostov-on-Don, Gagarina,1 DSTU \\
\hline
\end{tabular}

